***POSTPRINT: This is the revised version of a manuscript that was published in Palliative and Supportive Care (2015), doi:10.1017/S1478951515000206***

Development of a Brief Measure of Generativity and Ego-Integrity for Use in Palliative Care Settings

Dean Vuksanovic

Murray Dyck

Heather Green

Griffith University 


\begin{abstract}
Objective: To develop and test a brief measure of Generativity and Ego-Integrity that is suitable for use in palliative care settings. Methods: Two measures of Generativity and EgoIntegrity were modified and combined to create a new 11-item questionnaire which was then administered to 143 adults. A principal components analysis with oblique rotation was performed in order to identify underlying components that can best account for variation in the 11 questionnaire items. Results: The two-component solution was consistent with the items that, on conceptual grounds, were intended to comprise the two constructs assessed by the questionnaire. Conclusions: Results suggest that the selected 11 items were good representatives of the larger scales from which they were selected, and they are expected to provide a useful means of measuring these concepts near the end of life.
\end{abstract}




\section{Development of a Brief Measure of Generativity and Ego-Integrity for Use in Palliative Care Settings}

Understanding the psychological and social aspects of the final stages of human development is essential to providing optimal care to palliative care patients. In Erik Erikson's (1963) psychosocial theory of lifespan development, middle adulthood was conceptualised as an active and dynamic interplay between generativity and stagnation. Generativity includes provision of care and guidance to future generations, maintaining productivity through work or other activities, and a sense of leaving a lasting legacy. On the other hand, stagnation refers to apathy, lack of contribution to society, preoccupation with own needs and lack of care for others. Although critical in middle adulthood, Erikson and Erikson (1997) acknowledged that generativity is also essential to successful ageing among older adults as well.

In comparison, late adulthood was conceptualised by Erikson as an interplay between ego integrity and despair. Ego integrity includes looking back on one's life with a sense of meaning, acceptance of past life events, sense of growing wise with age and absence of death anxiety. Despair refers to a sense of disappointment with life's trajectory, guilt or regret about past events and a poor sense of accomplishment in life. Successful transition through these stages involves reaching a balance between their opposing poles (Van Hiel, Mervielde, \& De Fruyt, 2006) and incorporating both poles into a dynamic and complex understanding of the world (Torges, Stewart \& Duncan, 2008).

Erikson's theory has served as a basis for investigations on psychosocial development through the lifespan. There is evidence for the validity of both the generativity and egointegrity stages (Bradley, 1997; Bradley \& Marcia, 1998; James \& Zarrett, 2006; Hearn et al., 2012). McAdams and de St. Aubin (1992) developed and tested a comprehensive model of 
generativity that encompasses inner cognitions, desires, generative behaviours and cultural demands. An increased sense of generativity was associated with self-report indices of life satisfaction, happiness, self-esteem, goal stability, and a sense of coherence in life, and was negatively associated with depression (McAdams \& Azarow, 1996). Similarly, achieving a sense of ego-integrity was negatively associated with depression and positively associated with psychological well-being (Rylands \& Rickwood, 2001; James \& Zarrett, 2005). Consistent with Erikson's model, there is empirical evidence of a positive association between generativity and ego-integrity, including data from longitudinal studies (Torges, Stewart \& Duncan, 2008).

Measurement of generativity and ego-integrity has typically involved analyses of selfreport questionnaires, behavioural checklists and autobiographical recollections. However, the intended aims, wording of items and length of administration of such questionnaires are not readily suitable for use with older people (Schoklitsch \& Baumann, 2011) or with palliative care patients whose health is typically deteriorating. Similarly, qualitative analyses of life narratives depend on participants being motivated and able to take part in the relatively lengthy process of life review. Measures with excellent face validity for use with palliative care patients (e.g., Patient Dignity Inventory; Chochinov, Hassard, McClement, Hack, Kristjanson, Harlos, et al., 2008) include, at best, single-item measures of generativity and ego-integrity. No measure has been designed specifically to assess these concepts in the palliative patient population and this is a significant barrier in understanding their importance at, or near, the end of life. In order to address this issue, the aim of this study was to develop and evaluate a measure of generativity and ego-integrity that would be suitable for use in palliative care settings.

Scale Development 
The new brief measure of generativity and ego-integrity was based on two existing and validated measures of these concepts that were derived from Erikson's psychosocial theory of lifespan development: the Loyola Generativity Scale (McAdams \& de St. Aubin, 1992), and Ryff and Heincke’s (1983) Ego-Integrity Questionnaire. Both measures have good internal consistency, test-retest reliability, and convergent and discriminant validity. Twenty items from the Loyola Generativity Scale were grouped into their five theoretical components (McAdams \& de St. Aubin, 1992) after which six items were selected based on their representativeness of each theoretical component, and suitability for administration to palliative care patients (Appendix A). Similarly, five items were selected from the Ryff and Heincke’s Ego-Integrity Questionnaire based on their representativeness of the theoretical concept of Ego-Integrity and suitability for administration to palliative care patients (Appendix B).

Minor adjustments to wording of original items were made to five original items from the Loyola Generativity Scale and three original items from Ryff and Heincke’s Ego-Integrity Questionnaire, in order to further improve the face validity of items. The selected 11 items were combined into one measure and a 5-point Likert scale (strongly disagree, disagree, neutral, agree, strongly agree) was utilised. The final measure was named the Brief Measure of Generativity and Ego-Integrity (Appendix C).

\section{Method}

\section{Participants}

Participants were 143 adults living in New Zealand who were recruited via a researchoriented website, www.researchstudies.co.nz, after the research had been approved by a Human Resesarch Ethics Committee. All participants completed the new questionnaire and a demographics questionnaire on-line; no financial or other compensation was provided. This sample size is adequate for factor-analytic studies of 11-item questionnaires (Tabachnick \& 
Fidell, 2001). The mean age of the sample was 44.9 years (SD = 13.9; range 20-82). The majority of the sample were women (78.3\%). The median number of children was two, ranging between none and seven children, with $72.7 \%$ of participants having at least one child. The most frequent marital status was married (46.9\%), followed by never being married (21.7\%), defacto (14\%), separated or divorced (13.3\%) and widowed (4.2\%). The majority of the sample completed one or more years of tertiary education (77.5\%), while the rest either completed high school (15.5\%) or did not complete high school (7\%). The majority were currently working and/or studying (80.1\%), while remaining participants were retired $(11.3 \%)$ or semi-retired $(8.5 \%)$.

\section{Results}

Data were screened and the factorability of 11 questionnaire items was examined. A principal components analysis was used to identify the latent structure of the items to check if generativity items loaded together on one latent variable and if ego-integrity items loaded together on a second latent variable. Oblique (oblimin) rotation was performed due to theoretical and empirical relationships between generativity and ego-integrity. Two empirical indices regarding the data's correlation matrix revealed that it was suitable for factor analysis: Bartlett's test of sphericity was significant, $\chi^{2}(55)=423.37, p<0.001$, and Kaiser's measure of sampling adequacy was .82. Parallel analysis was conducted in order to accurately determine the number of components to retain (O’Connor, 2000). Two factors exceeded the parallel test cut-off (3.94>1.61, 1.63>1.43, respectively) and explained the total of $50.57 \%$ of variance. The two-factor solution (Appendix D) showed that the six Generativity items from the Loyola Generativity Scale had the highest loadings on the first factor. Four out of five Ego-integrity items from the Ryff and Heincke’s (1983) Ego-Integrity Questionnaire had the highest loadings on the second factor while the remaining item, "I feel 
contented with what I have accomplished in my life,” had the highest loading on the first factor.

Given that the Ego Integrity items are more relevant and applicable to middle and late adulthood, it was unclear whether the same latent structure obtained for the whole sample would be present in older participants. Therefore, factor analysis was repeated with the 80 participants who were at least 40 years old. The assumptions of sampling adequacy (KMO = 0.80 ) and sphericity (Bartlett's test, $\chi^{2}(55)=324.27, p<0.001$ ) were met. Principal components analysis with oblique (Oblimin) rotation was repeated with all 11 items. Similar to the previous analysis, two factors exceeded the parallel test cut-off $(4.53>1.83,1.73>1.58$, respectively) and explained the total of $56.90 \%$ of variance. The two-factor solution (Appendix E) showed that the six Generativity items had the highest loadings on the first factor and the five Ego-integrity items had the highest loadings on the second factor.

Finally, Cronbach's $\alpha$ was computed for the Generativity and Ego-Integrity subscales in order to determine their internal consistency. The $\alpha$ coefficients of both subscales (.78 and .73, respectively) suggested acceptable internal consistency, particularly as the total number of items in each scale was relatively low. The $\alpha$ coefficients further improved (.83 and .81 , respectively) to demonstrate good internal consistency when only data from participants 40 years and above were included. No improvements in internal consistency were found with deletion of any items in either of the two analyses.

\section{Discussion}

The aim of this study was to develop and evaluate a brief self-report measure of Erikson's concepts of Generativity and Ego-Integrity for use with participants who have a limited life expectancy. Results showed that the 11 selected items were good representatives of the larger scales from which they were selected in that they were able to consistently and efficiently measure aspects of Generativity and Ego-Integrity. This was particularly the case 
when middle aged and older adults were included in the analysis, in line with the theoretical and empirical models of these two concepts. The resulting 11-item questionnaire addresses a number of difficulties in reliably measuring sense of Generativity and Ego-Integrity in palliative care settings. Firstly, the wording of items and their relatively fast administration time would allow for more efficient assessment among participants who may be medically unwell, have reduced energy levels or shorter attention spans. Secondly, the use of a standardised measurement of Generativity and Ego-Integrity allows for direct theoretical and empirical comparisons of these two concepts whilst eliminating challenges associated with comparison of measures that may significantly differ to each other. This is particularly important given that Erikson’s psychosocial stages are both sequential and interrelated (Erikson, 1982). Finally, the inherent flexibility of this measure allows for further modifications and testing, as required.

The development of this brief self-report measure takes us closer to being able to assess and understand the importance of sense of Generativity and Ego-Integrity in palliative care settings. However, further evaluations of this measure are required in order to determine its utility at or near end of life, including (a) further testing with participants with limited lifeexpectancy, (b) further validation of the subscales by examining their associations with other relevant measures, and (c) inclusion of items controlling for the possible effect of social desirability. As such, this measure is likely to further evolve with subsequent research and testing. Of note is that a comprehensive multimodal approach to assessment of Erikson's psychosocial stages in palliative care settings would also need to include measurement of population-specific behavioural indicators and narrative accounts (McAdams \& de St Aubin, 1992) as well as consideration of various time perspectives (e.g. past, present, future) and inclusion of family perspectives (Schoklitsch \& Baumann, 2011). Therefore, further development and testing of other assessment tools and methodologies is needed in order to 
comprehensively assess Erikson’s psychosocial stages among palliative care patients.

Overall, the newly developed Brief Measure of Generativity and Ego-Integrity possesses good initial psychometric properties and contributes to our ability to assess these concepts among people who have a limited life expectancy. 


\section{References}

Bradley, C. (1997). Generativity-stagnation: Development of a status measure. Developmental Review, 17, 262-290.

Bradley, C. L., \& Marcia, J. E. (1998). Generativity-stagnation: A five category model. Journal of Personality, 66, 39-64.

Chochinov, H. M., Hassard, T., McClement, S., Hack, T., Kristjanson, L. J., Harlos, M., et al. (2008). The Patient Dignity Inventory: A novel way of measuring dignity-related distress in palliative care. Journal of Pain and Symptom Management, 36, 559-571

Erikson, E. H. (1963). Childhood and society (2nd ed.). New York: Norton.

Erikson, E. H. (1982). The life cycle completed: A review. New York: Norton.

Erikson, E. H., \& Erikson, J. M. (1997). The life cycle completed: Extended version with new chapters on the ninth stage of development. New York: Norton \& Comp.

Hearn, S., Saulnier, G., Strayer, J., Glenham, M., Koopman, R., \& Marcia, J. E. (2012). Between integrity and despair: Toward construct validation of Erikson's eighth stage. Journal of Adult Development, 19, 1-20.

James, J. B., \& Zarrett, N. (2005). Ego integrity in the lives of older women: A followup of mothers from the Sears, Maccoby and Levin (1951) patterns of child rearing study. Journal of Adult Development, 12, 155-167.

McAdams, D. P., \& Azarow, J. (1996). Generativity in black and white: Relations among generativity, race, and well-being. Paper presented at the convention of the American Psychological Association, Toronto, Canada.

McAdams, D. P., \& St. Aubin, E. de (1992). A theory of generativity and its assessment through self-report, behavioral acts, and narrative themes in autobiography. Journal of Personality and Social Psychology, 62, 1003-1015. 
O’Connor, B. P. (2000). SPSS and SAS programs for determining the number of components using parallel analysis and Velicer’s MAP test. Behavior Research Methods, Instruments, \& Computers, 32, 396-402.

Ryff, C. D., \& Heincke, S. G. (1983). Subjective organization of personality in adulthood and aging. Journal of Personality and Social Psychology, 44, 807-816

Rylands, K. J., \& Rickwood, D. J. (2001). Ego-integrity versus ego-despair: The effect of "accepting the past" on depression in older women. International Journal of Aging and Human Development, 53, 75-89.

Schoklitsch, A., \& Baumann, U. (2011). Measuring generativity in older adults: The development of new scales. GeroPsych: The Journal of Gerontopsychology and Geriatric Psychiatry, 24, 31-43.

Tabachnick, B. G., \& Fidell, L. S. (2001). Using multivariate analysis. Boston: Allyn and Bacon.

Torges, C. M., Stewart, A. J., \& Duncan, L. E. (2008). Achieving ego integrity: Personality development in late midlife. Journal of Research in Personality, 42, 1004-1019.

Torges, C. M., Stewart, A. J., \& Duncan, L. E. (2009). Appreciating life’s complexities: Assessing narrative ego integrity in late midlife. Journal of Research in Personality, 43, 66-74.

Van Hiel, A., Mervielde, I., \& De Fruyt, F. (2006). Stagnation and generativity: Structure, validity, and differential relationships with adaptive and maladaptive personality. Journal of Personality, 74, 543-573. 


\section{Appendix A}

Loyola Generativity Scale (McAdams \& de St. Aubin, 1992) and its five theoretical bases.

1. I try to pass along the knowledge I have gained through my experiences*^

3. I think I would like the work of a teacher

12. I have important skills that I try to teach others

19. People come to me for advice

5. I do not volunteer to work for a charity

15. I feel as though I have done nothing of worth to contribute to others*^

18. I have a responsibility to improve the neighbourhood in which I live

20. I feel as though my contributions will exist after I die

4. I feel as though I have made a difference to many people

6. I have made and created things that have had an impact on other people

8. I think that I will be remembered for a long time after I die*

10. Others would say that I have made unique contributions to society

13. I feel that I have done nothing that will survive after I die*^

14. In general, my actions do not have a positive effect on other people

7. I try to be creative in most things that I do

17. Other people say that I am a very productive person*^

2. I do not feel that other people need me

9. I believe that society cannot be responsible for providing food and shelter for all homeless people

11. If I were unable to have children of my own, I would like to adopt children

16. I have made many commitments to many different kinds of people, groups, and activities in my life*^
Passing on knowledge and skills to others, especially to the next generation

Significant contributions for the betterment of one's community or neighbourhood
Actions that that will be remembered for a long time, have a lasting impact, and leave an enduring legacy

\section{Creativity and productivity}

Caring for and taking responsibility for other people

* denotes items that were selected in the final brief measure of Generativity;

$\wedge$ denotes items where minor modifications to original wording were made. 


\section{Appendix B}

Ryff and Heincke’s (1983) Ego-Integrity Questionnaire

If I had to do it all over again, there are very few things about my life that I would change

1. I feel generally contented with what I have accomplished in my life*^

2. I wish my life were just beginning so I could avoid many of the mistakes I made earlier in my life

3. In general, I would say I have few regrets about my past life

4. All in all, I am comfortable with the choices I made regarding my life's work

5. I still feel angry about certain of my childhood experiences*^

6. If I had had just a couple more lucky breaks, my life would have turned out much differently

7. My life has been fulfilling, and I am not frightened by the thought of death*

8. If I could turn back the clock, there are many things I would do differently

9. It doesn’t bother me to think about goals I haven’t reached and probably never will

10. Reading old diaries and letters usually brings more pain than pleasure

11. One of my greatest disappointments is that I have not been able to do more traveling

12. I often wish I had been born during a different period of history

13. There are many people whose life I would prefer to my own

14. When I consider the ups and downs of my past life, they somehow fit together in a meaningful way*

15. There are some disappointments in life I will never be able to accept*^

\footnotetext{
* denotes items that were selected in the final brief measure of Ego-Integrity;
}

$\wedge$ denotes items where minor modifications to original wording were made. 


\section{Appendix C}

Items Comprising the Brief Measure of Generativity and Ego-Integrity

1. I pass along the knowledge that I have gained through my experiences

2. I think that I will be remembered for a long time after I die

3. I am not making a meaningful and lasting contribution to other people

4. I am committed to many different kinds of people, groups, and activities

5. I have done nothing that will survive after I die

6. Other people would say that I am very productive

7. I feel contented with what I have accomplished in my life

8. I still feel angry about some of my life experiences

9. My life has been fulfilling, and I am not frightened by the thought of death

10. When I consider the ups and downs of my past life, they somehow fit together in a meaningful way

11. I have had disappointments in life that I will never be able to accept 


\section{Appendix D}

Pattern matrix for the two-factor solution (total sample)

Factor 1

Factor 2

(Generativity) (Ego-Integrity)

I pass along the knowledge that I have gained through my .44 .13

experiences

I think that I will be remembered for a long time after I die

.75

I am not making a meaningful and lasting contribution to other

.72

$-.078$

people

I am committed to many different kinds of people, groups, and

.76

activities

I have done nothing that will survive after I die

.75

Other people would say that I am very productive

.62

.07

I feel contented with what I have accomplished in my life

.52

.31

I still feel angry about some of my life experiences

.07

.75

My life has been fulfilling, and I am not frightened by

.21

.58

the thought of death

When I consider the ups and downs of my past life, they

somehow fit together in a meaningful way

I have had disappointments in life that I will never be able to

$-.28$ accept 


\section{Appendix E}

Pattern matrix for the two-factor solution (participants 40 years old and above)

(Generativity) (Ego-Integrity)

\begin{tabular}{|c|c|c|}
\hline I pass along the knowledge that I have gained through my & .60 & .02 \\
\hline \multicolumn{3}{|l|}{ experiences } \\
\hline I think that I will be remembered for a long time after I die & .74 & .06 \\
\hline I am not making a meaningful and lasting contribution to other & .67 & .03 \\
\hline \multicolumn{3}{|l|}{ people } \\
\hline I am committed to many different kinds of people, groups, and & .78 & -.13 \\
\hline \multicolumn{3}{|l|}{ activities } \\
\hline I have done nothing that will survive after I die & .84 & -.00 \\
\hline Other people would say that I am very productive & .66 & .09 \\
\hline I feel contented with what I have accomplished in my life & .36 & .47 \\
\hline I still feel angry about some of my life experiences & .13 & .74 \\
\hline My life has been fulfilling, and I am not frightened by & .08 & .74 \\
\hline \multicolumn{3}{|l|}{ the thought of death } \\
\hline When I consider the ups and downs of my past life, they & .10 & .68 \\
\hline \multicolumn{3}{|l|}{ somehow fit together in a meaningful way } \\
\hline I have had disappointments in life that I will never be able to & -.26 & .94 \\
\hline accept & & \\
\hline
\end{tabular}

